\title{
The Effects of Credit Risk and Funding on the Pricing of Uncollateralized Derivative Contracts
}

\section{R. Abbate}

SunGard

Quantitative Analytics

Received December 2014; accepted April 2015; published June 2015

Copyright (C) 2015 by author and Scientific Research Publishing Inc.

This work is licensed under the Creative Commons Attribution International License (CC BY).

http://creativecommons.org/licenses/by/4.0/

c) (i) Open Access

\begin{abstract}
Banks are subject to higher capital charges for transactions that are uncollateralized and typically incorporate the cost of counterparty credit risk into the prices of derivative contracts quoted to commercial end-users. Many banks have adopted a framework under which they incorporate the cost of funding and liquidity into the risk-neutral price of uncollateralized derivative contracts. The Law of One Price no longer holds, as the inclusion of credit risk and funding results in different banks quoting inconsistent prices for the same transaction. The purpose of this paper is to outline and quantify the effects of counterparty credit risk, one's own credit risk and funding costs on the pricing of uncollateralized financial derivative contracts. We examine Credit Valuation Adjustment (CVA), Debit Valuation Adjustment (DVA) and Funding Valuation Adjustment (FVA).
\end{abstract}

\section{Keywords}

Credit Valuation Adjustment (CVA), Debit Valuation Adjustment (DVA), Funding Valuation Adjustment (FVA), Potential Future Exposure (PFE), Uncollateralized Derivatives Pricing 


\section{Introduction}

In recent years, derivatives pricing has become increasingly complex. Prior to the onset of the global financial crisis in 2007, market participants focused primarily on accurately pricing the market risk of derivative contracts. The quantitative models used to price financial derivative contracts were based on the simplifying assumption of "risk-neutrality" ${ }^{1}$. The prices of derivative contracts in liquid markets quoted to clients by different banks were generally consistent.

As the financial crisis unfolded, the assumption of risk-neutrality was challenged. Since then, market participants generally agree that the underlying assumptions of market completeness and the ability to create a riskless replicating portfolio have been invalidated. It is not possible to borrow and lend limitlessly at a "risk-free" rate and the payment of cash flows resulting from derivative contracts is all but certain.

The financial crisis has taught us that no institution is "too big to fail”. Market participants have become keenly aware of the importance of credit risk and funding costs. Today, banks commonly introduce the cost of credit risk into the price of derivative contracts, altering the most fundamental assumptions of risk-neutral pricing. Many banks even incorporate the cost of funding into trade valuation. Including the costs of credit risk and funding could result in a client receiving inconsistent prices from different banks for the same derivative contract. The so-called Law of One Price no longer holds and many previously robust valuation models have been rendered obsolete.

In this paper, we discuss the ways in which market participants adjust the risk-neutral price of financial derivative contracts to account for the effects of counterparty credit risk, one's own credit risk and the cost of funding. We discuss the impact of Credit Valuation Adjustment (CVA), Debit Valuation Adjustment (DVA) and Funding Valuation Adjustment (FVA), collectively referred to as $\mathrm{xVA}$, on the price of a derivative contract.

\section{The "Unintended Consequences" of Legislation}

In the aftermath of the global financial crisis, regulators sought to promote transparency and to reduce systemic risk in the previously unregulated market for over-the-counter (OTC) financial derivative contracts. Title VII of the Dodd-Frank Act grants the Commodity Futures Trading Commission (CFTC) the authority to mandate central clearing and competitive trade execution for financial derivative contracts ${ }^{2,3}$. Although some end-users with large transaction volume and the ability to set aside sufficient cash for margin calls have benefitted from reduced costs, most end-users transact infrequently and view central clearing and competitive trade execution as not only costly, but also operationally burdensome. Fortunately, the Board of Governors of the Federal Reserve System and the CFTC recently proposed legislation that includes exemptions for certain end-users who are not "financial entities" and who transact derivatives in order "to hedge or mitigate commercial risk". Exempt firms would not be subject to the requirements of central clearing and margin, or competitive trade execution on a swap execution facility (SEF) or designated contract market (DCM). Consequently, however, these exempt end-users are subject to increased dealing costs, including the cost of credit and funding, which we discuss in Section 3 of this paper.

In May 2011, the author discussed the evolving regulatory landscape with former U.S. Senator Christopher "Chris" Dodd during an energy risk management conference in Houston, Texas. When asked about the seemingly burdensome nature of the then-proposed central clearing and margin requirements, Senator Dodd indicated that “... unfortunately, there will be some unintended consequences [of the legislation]... but, we tried to get it right.”

In September 2014, the International Swaps and Derivatives Association, Inc. (ISDA) conducted a "survey of issues and trends for the derivatives end-user community” (ISDA, 2014). The vast majority of respondents, who represent various geographical regions and industry verticals, indicated that financial derivatives will continue to be an integral component of their risk management strategies. Notably, one of the chief concerns among the majority of respondents was the increased cost of hedging.

\footnotetext{
${ }^{1}$ For additional detail, see Section 3 of the article entitled "CSA Discounting: Impacts on the Risk and Valuation of Commodity Derivatives" in the September 2014 publication of the Journal of Financial Risk Management (Abbate, 2014).

${ }^{2}$ Section 1a (47) of the Commodity Exchange Act (CEA) defines the term swap broadly as “...a put, call, cap, floor, collar, or similar option of any kind that is for the purchase or sale, or based on the value, of 1 or more interest or other rates, currencies, commodities, securities, instruments of indebtedness, indices, quantitative measures, or other financial or economic interests or property of any kind."

${ }^{3}$ On November 16, 2012, the Department of the Treasury issued a determination that foreign exchange forwards and foreign exchange swaps should not be regulated under the CEA and should therefore be exempted from the definition of "swap" under the CEA for the purposes of margin requirements, trade execution and mandatory clearing. Other foreign exchange derivatives such as options, swaps, cross-currency swaps and non-deliverable forwards are not exempt.
} 


\section{Decomposing the Cost of Credit and Funding}

Many market practitioners incorporate the market price of counterparty credit risk and one's own credit risk into their valuation models. Some participants even incorporate the cost of funding into the prices quoted to commercial end-users. In the sections that follow, we examine the effects of credit risk and funding costs on the prices of financial derivative contracts.

\subsection{The Counterparty's Credit Risk}

Although research on counterparty credit risk (CCR) began in the 1990s, market participants became keenly aware of its importance as the global financial crisis of 2007-2008 unfolded. Regulations such as the Dodd-Frank Act and the Third Basel Accord (Basel III), along with fair-value accounting rules such as Accounting Standards Codification (ASC) Topic 820 and International Financial Reporting Standards (IFRS) 13, require credit risk to be reflected in the fair value measurement of financial derivative contracts. In order to accurately price a derivative contract, one must include the credit risk associated with one's counterparty.

Historically, banks have defaulted very rarely and commercial end-users have defaulted only occasionally. In December 2009, the Basel Committee on Banking Supervision (BCBS) concluded that approximately one-third of the losses during the financial crisis can be attributed to actual counterparty default. The remaining two-thirds of the losses resulted from the negative impacts of credit market volatility on banks' earnings (Bank for International Settlements, 2009). The BCBS consultative document indicated that “... the current framework addresses CCR as a default and credit mitigation risk, but does not fully account for market value losses short of default” (Bank for International Settlements, 2009). In response to this shortcoming, the BCBS introduced a new capital charge in Basel III: the Credit Valuation Adjustment (CVA).

CVA is the present value of the expected loss on a trade or portfolio of trades due to default by one's counterparty. Stated differently, CVA is a price that represents the difference in value between a default-free value of a counterparty's portfolio and the value of the same portfolio taking into account the possibility of the counterparty's default. CVA measures the sensitivity of a trade's exposure to movements in a counterparty's credit spread - not counterparty default, per se.

The approaches to calculate CVA range from relatively simple "add-on" methods to complex Monte Carlo simulation. The chosen method depends principally on the sophistication and various resources available to the market participant. To compute CVA, banks commonly rely on Monte Carlo simulation, which becomes computationally intensive as the size of the portfolio and the number of simulated risk factors (e.g. interest rates, foreign exchange rates, commodity prices, etc.) increase. The reader is referred to Appendix A of this paper for the general process by which CVA would be computed under a Monte Carlo simulation approach.

Prior to the onset of the financial crisis, banks typically viewed themselves as default-free, while viewing their corporate end-user clients as subject to default. If both parties were to agree to this framework, and assuming that there is no collateral posted ${ }^{4}$, as is often the case with transactions occurring with commercial end-users (Watt, 2011), then we have what is referred to as Unilateral CVA (UCVA). UCVA is the risk-neutral expectation of the discounted loss and can be expressed from the bank's perspective as

$$
U C V A=L G D \int_{0}^{T} P(t) E E(t) d P D_{C}(0, t)
$$

where $L G D$ (Loss Given Default) equals one minus the recovery rate ${ }^{5}, P(t)$ is the discount factor process for time $t$, $E E(t)$ is the risk-neutral expectation of the exposure to a given counterparty at time $t$ and $d P D_{C}(0, t)$ is the counter party's default probability distribution. These default probabilities can be derived by bootstrapping the counterparty's credit default swap (CDS) spreads or reasonable proxies thereof, taking into account the counterparty's geographic region, industrial sector and rating (sometimes referred to as "mark-to-matrix"). We note in Equation (3.1) that the exposure is

\footnotetext{
${ }^{4}$ On September 3, 2014, the Board of Governors of the Federal Reserve system and other federal 'prudential regulators' re-proposed rules that would exempt non-financial "commercial” end-users from posting margin on non-cleared derivatives. On September 17, 2014, the CFTC re-proposed rules that are largely identical to those re-proposed by the prudential regulators.

${ }^{5}$ Typically $35 \%$ to $40 \%$ for non-distressed entities.
} 
independent of counterparty default (i.e. there is no "wrong-way" risk ${ }^{6}$ ) and that the exposures are obtained using risk-neutral probabilities.

In order to compute the UCVA of a fixed/floating swap, for example, we simulate $j$ number of relevant risk factors using $n$ number of random variables across $i$ number of time steps. Credit exposure can be viewed as a function of the risk factors that drive the values of the derivative contracts in the portfolio. Let us assume that a given risk factor $S$ follows a geometric Brownian motion with drift $\mu$ and volatility $\sigma$. Let us further assume an initial value of zero, a local drift of $2 \%$ and a diffusion of $25 \%$. Figure 1 depicts the evolution of risk factor $S$ based on fifty ${ }^{7}$ simulated paths ${ }^{8}$ across 120 time steps. The simulated values of risk factor $S$ greater than zero represent an expected positive exposure for the payer of the swap at each point in time.

The Expected Exposure $(E E)$ is the mean of the distribution of positive exposures at any particular future date prior to the maturity of the longest-dated transaction in the netting set ${ }^{9}$. The EE at time $t$ can be written as

$$
E E(t)=\mathbb{E}\left[\max \left(\sum_{i=1}^{N} V_{i}(t), 0\right)\right]
$$

where $\mathbb{E}$ denotes the expectation operator, $N$ denotes the number of transactions in the netting set and $V_{i}(t)$ denotes the value of the $i$-th trade at time $t$. Figure 2 depicts the Expected Exposure based on the simulations in Figure 1 .

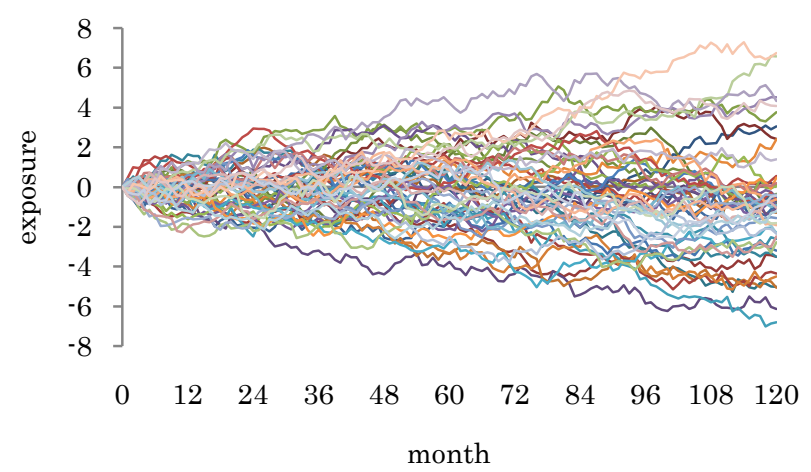

Figure 1. Simulated Exposure; $\mu=2 \%, \sigma=25 \%$. Source: Author.

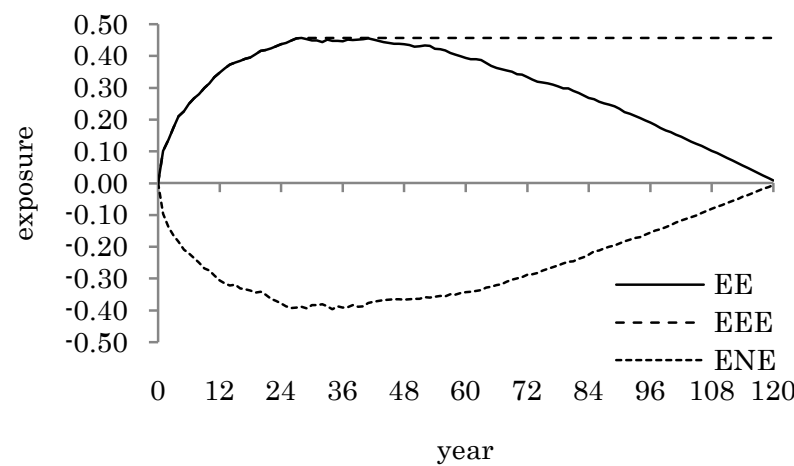

Figure 2. Expected Exposure, Effective Expected Exposure, Expected Negative Exposure. Source: Author.

\footnotetext{
${ }^{6}$ Occurs when exposure to a particular counterparty is adversely correlated with the credit quality of that counterparty.

${ }^{7}$ For illustration purposes; in practice, we set $n>5000$.

${ }^{8}$ We use a Marsenne Twister pseudo-random number generator to create standard normal random variables.

${ }^{9} \mathrm{~A}$ group of transactions with a single counterparty that are subject to a legally enforceable bilateral netting agreement.
} 
The Effective Expected Exposure (EEE) at a specific date, as depicted in Figure 2, is the maximum Expected Exposure occurring at that date or any prior date (i.e. constrained to be non-decreasing) and is expressed as

$$
E E E\left(t_{E}\right)=\max _{t \in\left[0, t_{E}\right]}(E E(t))
$$

We apply the EE from the simulations in Figure 1, the term structure of U.S. dollar discount factors (as of September 19, 2014) depicted in Figure 3 and the hypothetical CDS spreads depicted in Figure 4 to Equation (3.1). When assuming a recovery rate of $40 \%$, the CVA amounts to 0.04064 . We depict the CVA in Figure 5. Appendix B contains a table of results for counterparty default probability, EE and CVA.

The tenor of the trade and the creditworthiness of one's counterparty are the two primary drivers of CVA. Long-dated trades tend to be the most CVA-intensive. In general, the presence of a master netting agreement, collateral arrangements and termination provisions tend to reduce the exposure, and thus the UCVA.

We can extend Equation (3.1) and express CVA more formally as

$$
C V A=-\left(1-R_{c}\right) \mathbb{E}_{t}\left[\int_{t}^{T} \lambda_{c}(u)\left(v_{t}(u)-C(u)\right)^{+} P_{E}(t, u) d u\right]
$$

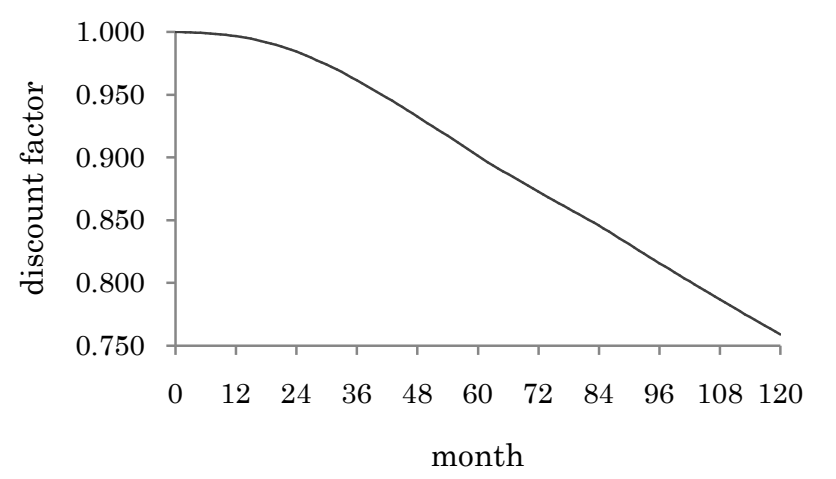

Figure 3. Term structure of U.S. dollar discount factors. Source: Author.

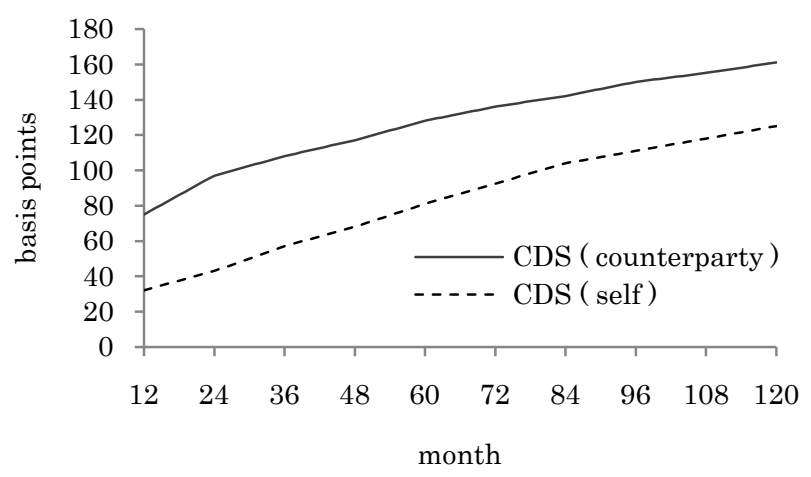

Figure 4. Term structure of CDS spreads. Source: Author. 


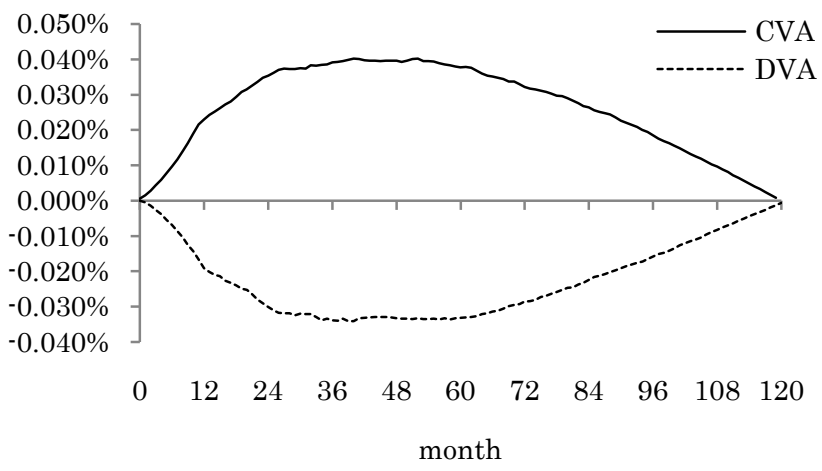

Figure 5. Credit Valuation Adjustment, Debit Valuation Adjustment. Source: Author.

where $R_{c}$ denotes the recovery rate applied to one's counterparty, $\lambda_{c}$ denotes the survival probability (hazard rate) applied to one's counterparty, $v_{t}$ denotes the future value of the derivative contract, $C$ denotes the value of the collateral and $P$ denotes the discount factor ${ }^{10}$. In Equation (3.4), we are concerned with the uncollateralized positive exposure.

Basel III mandates the calculation of a CVA capital charge, the purpose of which is to improve banks' ability to withstand potential mark-to-market losses associated with deterioration in the creditworthiness of their counterparties to non-cleared derivative contracts. Banks also seek to optimize the use of regulatory capital by determining the marginal impact of trades on risk weighted assets and regulatory capital. At this time, most of the large global banks have incorporated CVA into the prices of derivatives contracts they quote to clients. These banks commonly recover the cost of the CVA by pricing it upfront. The quotes from offshore banks may differ from those of local banks in that the offshore banks may include a sovereign credit risk premium in the CVA calculation.

The CVA calculation depends on the entire portfolio of transactions. Thus, it is not possible to assign a mark-to-market value to a particular transaction without consideration of the other transactions in the portfolio. Additionally, CVA involves significant model risk. According to Brigo et al. (2013), “...five banks might compute CVA in 15 different ways".

Basel III mandates that banks can use two different methods to calculate CVA. The advanced approach requires the use of Monte Carlo simulation, wrong-way risk, stress testing, back testing and stressed effective expected positive exposure (EEPE) ${ }^{11}$. This approach, which applies to most of the largest banks, results in lower capital requirements. To the extent that a particular bank has regulatory approval to use the Internal Model Method (IMM) for calculating counterparty credit risk capital, then the advanced approach must be used. Otherwise, banks are required to use the standardized approach, which allows for two methods. The Current Exposure Method (CEM), which allows banks to apply relatively crude add-ons to the mark-to-market value of transactions, has been widely criticized for its significant shortcomings, most notably understating the benefit of netting and collateral. The Standardized Method (SM), which relies on a formulaic approach, is more risk-sensitive than the CEM. The new standardized approach (SA-CCR), which replaces CEM and SM and is intended to better recognize the effects of netting and collateral, becomes effective on January 1, 2017.

The management of CVA varies considerably across organizations. Some banks calculate CVA only for the purposes of accounting/reporting and regulatory capital. Others banks have implemented a CVA pricing framework, under which CVA is incorporated into the inception price of client trades. Because a counterparty's CDS spreads can exhibit high volatility (particularly during times of market stress), some banks have established centralized CVA desks, which consolidate and centrally manage the enterprise-wide CVA. These CVA desks have a mandate that ranges from passively hedging the P\&L associated with CVA volatility to actively managing CVA by trading specific reference entities in order to allow the bank to transact additional business with a client whose credit line would otherwise prevent such

\footnotetext{
${ }^{10}$ Typically a blended interest rate that takes into account the interest rate of the collateral and the funding rate.

${ }^{11} \mathrm{EEPE}$ is the weighted average of the expected exposure.
} 
trading. Banks may enter into single-name credit default swaps, single-name contingent credit default swaps (CCDS) or other equivalent hedging instruments which reference the entity directly. The lack of liquidity in the CDS market and the unavailability of single-name CDS are often cited as challenges to hedging CVA volatility.

In the case of a 5-year uncollateralized trade with a commercial end-user, the increase in required capital could be significant. In view of higher capital charges, some banks have reevaluated the economics of their OTC trading businesses. Meanwhile, many smaller banks have not implemented a CVA pricing framework, allowing them to quote more competitive prices than the larger global banks and to compete for client business that would not have been possible before the large global banks implemented their CVA pricing frameworks. Until smaller regional banks implement a CVA pricing framework, large global banks are left striking a delicate balance between prudent pricing and the need to win trades with end-user clients.

Legislators in the European Union have provided European banks an exemption from calculating a CVA capital charge for corporates, sovereigns and pension funds. Banks in the U.S. are justifiably concerned that the absence of a similar exemption in the U.S. rules gives an unfair pricing advantage to banks trading within the European Union, which are not required to hold capital against similar exposures. Other critics have argued that the CVA exemption is inconsistent with aims to achieve globally harmonized prudential requirements.

\section{Intermezzo: Potential Future Exposure}

Counterparty exposure is the larger of zero and the market value of a transaction or portfolio of transactions within a netting set that would be lost if a given counterparty were to default and there were zero recovery during a bankruptcy proceeding. Current Exposure (CE) is the current mark-to-market exposure to a given counterparty and is also referred to as the replacement cost. CE is not particularly useful as a credit risk metric, since it is a single point estimate and fails to provide a robust indication of credit risk at future points in time.

Potential Future Exposure (PFE), also referred to as Peak Exposure (PE), is a high percentile (e.g. 95\%) of the distribution of exposures at any particular future date prior to the maturity of the longest-dated transaction in the netting set. PFE is typically computed with simulation models (e.g. Monte Carlo simulation). For each future date $t$, the value of a transaction or portfolio of transactions with a given counterparty is simulated.

The curve $\mathrm{PE}(\mathrm{t})$ is the peak exposure profile up to the final maturity of the portfolio. If we denote the confidence interval as $\alpha$, then the peak exposure for a future scenario at time $t$ is written as

$$
P E(t)=\inf \{X(t): P[P F E(t) \geq X(t)] \leq 1-\alpha\}
$$

For example, PFE generated with 95\% statistical confidence represents the level of potential exposure that is exceeded with only $5 \%$ probability.

Netting agreements function to mitigate credit risk among counterparties. Under the terms of a netting agreement, transactions in the netting set with negative mark-to-market values are used to offset transactions with positive mark-to-market transactions; only the net positive mark-to-market value represents the credit exposure at the time of default. In the absence of a netting agreement, and assuming no recovery, we can express PFE as

$$
\operatorname{PFE}_{\Pi}(t)=\sum_{i=1}^{N} \max \left(V_{i}(t), 0\right)
$$

where $\Pi$ denotes the portfolio of transactions, $N$ denotes the number of transactions in the portfolio and $V_{i}(t)$ denotes the value of the $i$-th trade at time $t$.

In the presence of a netting agreement, we can express PFE as

$$
P F E_{\Pi}(t)=\max \left(\sum_{i=1}^{N} V_{i}(t), 0\right)
$$

The maximum value of $\operatorname{PFE}(t)$ over any given time horizon is referred to as the Maximum Potential Future Ex- 
posure (MPFE), as depicted in Figure 6.

PFE is analogous to Value-at-Risk (VaR), with a few exceptions. VaR represents exposure due to market losses (i.e. left tail of the distribution), while PFE represents exposure due to market gains (i.e. right tail of the distribution). Whereas VaR typically addresses a short time horizon, PFE looks many months or years into the future. Lastly, PFE represents a distribution of outcomes, rather than a single point estimate.

A counterparty's credit exposure profile can be segmented into a "diffusion phase" and an "amortization phase". During the diffusion phase, the passage of time increases the probability that the underlying risk factors drift significantly from their initial values. During the diffusion phase of the exposure profile, a trade has a long time to maturity, many remaining cash flows and is sensitive to market uncertainty. The diffusion is determined primarily by the volatility of the underlying risk factors. During the amortization phase, the passage of time results in a reduction in the number of cash flows that would need to be replaced in the event of default. During the amortization phase of the exposure profile, a trade has a short time to maturity, few remaining cash flows and has little sensitivity to market uncertainty. The offsetting nature of the diffusion phase and the amortization phase creates the humped-back appearance in a counterparty's exposure profile (assuming contracts do not have a final exchange of notional), as depicted in Figure 6. For trades with multiple cash flows, the PFE typically peaks at a point in time that is approximately one-third to one-half into the life of the transaction.

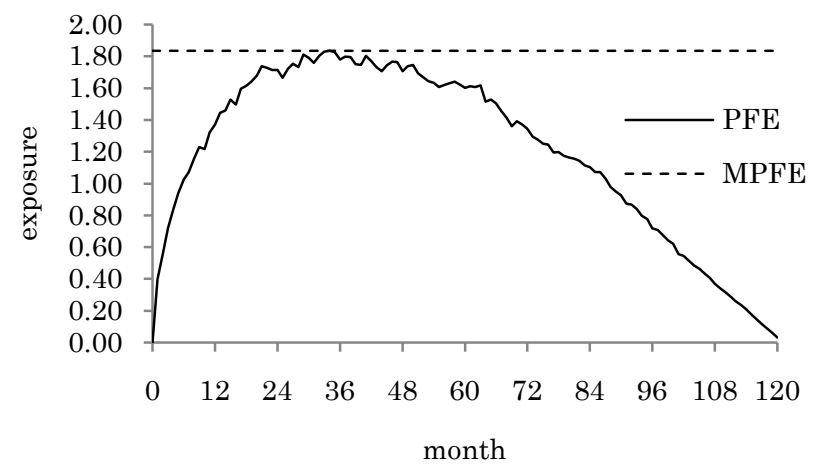

Figure 6. Potential Future Exposure at 95\% confidence. Source: Author.

\subsection{One’s Own Credit Risk}

Prior to the onset of the financial crisis, many banks relied on UCVA to manage counterparty credit risk. This approach is justified when one of the two parties to the transaction can be considered default-free, as many banks were prior to August 2007. In the aftermath of the financial crisis, however, we know that banks are susceptible to default.

Let us assume that two parties use UCVA to value a particular transaction. One party is a highly rated credit; the other party is not. The parties will likely arrive at different valuations for the same trade due to the differing assumptions of counterparty risk (e.g. probability of default) that each party assigns to the other. This asymmetry is addressed by incorporating Debit Valuation Adjustment ${ }^{12}$ (DVA). Unlike CVA, DVA represents the difference in value between a default-free portfolio and the value of the same portfolio that incorporates the possibility of the one's own default.

The inclusion of DVA has been widely debated and remains controversial. Companies record gains when their own creditworthiness deteriorates, and record losses when their own creditworthiness improves. When a firm's credit spreads widen, DVA increases, reflecting a reduction in the value of its liabilities resulting from the increased probability of default. For example, in Q1 2009, Citibank reported a positive mark-to-market due to a worsening of its credit quality, citing that "Revenues also included ... a net $\$ 2.5$ billion positive CVA on derivative positions, excluding monolines, mainly due to the widening of Citi’s CDS spreads” (Citibank, 2009). In October 2011, the Wall Street Journal reported that Goldman Sachs' "DVA gains in the third quarter totaled \$450 million, about \$300 million of which was recorded under its fixed-income, currency and commodities trading segment...” (Brigo et al., 2013).

\footnotetext{
${ }^{12}$ Also referred to as Debt Valuation Adjustment.
} 
There is an offsetting effect between CVA and DVA. If one party records a CVA loss, the other party records a corresponding DVA gain. The inclusion of DVA results in a Bilateral Valuation Adjustment (BVA), which is also referred to as Bilateral CVA (BCVA).

Notwithstanding the controversy, ASC 820 (formerly Statement of Financial Accounting Standards 157) defines fair value as "the price that would be received to sell an asset or paid to transfer a liability in an orderly transaction between market participants at the measurement date". Fair-value accounting standards require the inclusion of DVA in derivatives prices. ASC 820 “...clarifies that a fair value measurement for a liability reflects its nonperformance risk (the risk that the obligation will not be fulfilled). Because nonperformance risk includes the reporting entity's credit risk, the reporting entity should consider the effect of its credit risk (credit standing) on the fair value of the liability in all periods in which the liability is measured at fair value under other accounting pronouncements...” (Financial Accounting Standards Board, 2011). Despite the relevant accounting standards, Basel III no longer permits the offsetting of CVA with DVA.

We can express DVA as

$$
D V A=-\left(1-R_{s}\right) \mathbb{E}_{t}\left[\int_{t}^{T} \lambda_{s}(u)\left(v_{t}(u)-C(u)\right)^{-} P_{E}(t, u) d u\right]
$$

where $R_{s}$ denotes the recovery rate applied to one's self, $\lambda_{s}$ denotes the survival probability (hazard rate) applied to one's self, $v_{t}$ denotes the future value of the derivative contract, $C$ denotes the value of the collateral and $P$ denotes the discount factor. In Equation (3.8), which follows from Equation (3.4), we are concerned with the negative uncollateralized exposure. Figure 2 depicts Expected Negative Exposure (ENE), which is the mean of the distribution of negative exposures at any particular future date prior to the maturity of the longest-dated transaction in the netting set. The equation for ENE is identical to Equation (3.2), except that we replace the max function with the min function.

We apply the ENE from the simulations in Figure 1, the term structure of U.S. dollar discount factors (as of September 19, 2014) depicted in Figure 3 and the hypothetical CDS spreads depicted in Figure 4 to Equation (3.8). When assuming a recovery rate of $40 \%$, the DVA amounts to 0.02765 . We depict the DVA in Figure 5 . Appendix B contains a table of results for default probability, ENE and DVA.

Apart from its counterintuitive nature, another criticism of DVA is the difficulty one faces when attempting to hedge it or monetize it. Some argue that DVA is not merely an accounting adjustment, but instead can be monetized through replication strategies. Hedging DVA involves buying one's own bonds or, for example, selling a credit default swap on a basket of one's closely correlated peers (since a bank cannot sell credit default swaps on itself) ${ }^{13}$. Burgard and Kjaer (2010) derive a partial differential equation for the risky price of an asset by adapting the classical argument of Merton to take into account the possibility of default. However, Castagna (2012a) argues that DVA cannot be replicated by a dynamic strategy. A bank that buys back its own bonds is merely reducing its short position, not taking a long position in the bonds it issued. Castagna concludes that DVA is a cost, which should be deducted from a bank's equity, as the BCBS recommends.

\subsection{The Importance of the Credit Support Annex}

The Credit Support Annex (CSA), which is an optional component of the ISDA Master Agreement, functions to mitigate credit risk between counterparties and requires the party with a negative economic exposure to post collateral with the opposing party to the transaction if the exposure to that party exceeds a certain previously negotiated threshold. When default occurs, close-out netting rules typically apply. Multiple liabilities are netted into a single liability before the collateral is applied to the recovery. The Master Agreement defines the close-out amount as the amount of loss that the surviving party would incur to replace the economic equivalent of the pertinent transactions. The method by which the close-out amount is calculated is not well-defined by the Master Agreement.

CSA agreements are negotiated between parties. Standard parameters of the CSA include up/down thresholds, minimum transfer amounts, frequency of rebalancing and eligible collateral. Agreements can also include optionality, such as the choice of collateral type and the choice of currency - to name a few. The delivering party may also substitute collateral. The posting of collateral entails a cost for one party and a corresponding benefit for the other party. The re-

\footnotetext{
${ }^{13}$ Basel III does not recognize DVA hedge positions, which incur a capital charge.
} 
ceiver of the collateral eliminates or reduces its risk of loss conditional on default. When permitted to do so per the terms of the CSA, the collateral receiver re-hypothecates ${ }^{14}$ the collateral for other purposes until the time at which the collateral must be returned to the provider.

The CVA charge shrinks when exposure is collateralized. Some end-users have attenuated the CVA charge by signing a two-way credit support annex (CSA) agreement with their bank counterparties. However, CSA agreements with low margin thresholds and/or high margin call frequencies require the end-user to have adequate liquid assets and can present operational burdens (e.g. personnel to manage the collateral transfers, etc.).

Specific provisions of the CSA must be taken into account when pricing derivatives. Almost every CSA is unique. It has been said that "the CSA is the most exotic of exotic derivatives", making it difficult for end-users to compare price quotes among different banks. Given the friction embedded in the collateral posting and receiving process, there will always be some credit exposure between parties - even in the presence of a two-way CSA agreement. Clearly, the various parameters of the CSA can have a significant impact on xVA.

\subsection{The Cost of Funding}

Banks need cash to perform a number of operations, such as hedging and posting collateral. One key assumption of the Black-Scholes (1973) model is the ability to borrow and lend limitlessly at a risk-free interest rate. In practice, this is not possible - especially so in the wake of the financial crisis. There has been a contentious debate recently among market participants as to the appropriateness of incorporating the cost of funding and liquidity into the price of an uncollateralized derivative contract.

As an example, let us assume that a bank has an uncollateralized client trade that is offset by a collateralized trade with an inter-bank counterparty. Let us further assume that the client trade is in-the-money from the bank's perspective. The bank will not receive collateral from the end-user client, but would have to post collateral to its inter-bank counterparty. The bank's trading desk borrows this cash from its internal treasury (or from the money market), which represents a funding cost. Conversely, when the bank has an uncollateralized client trade that is out-of-the-money, the bank does not have to post collateral to the end-user client, but receives collateral from its inter-bank counterparty. If the collateral can be re-hypothecated, the trading desk benefits by lending the collateral to the bank's internal treasury or to the money market.

The Funding Cost Adjustment (FCA) can be expressed as

$$
F C A=-\mathbb{E}_{t}\left[\int_{t}^{T} \lambda_{F}(u)\left(v_{t}(u)-C(u)\right) P_{E}(t, u) d u\right]
$$

where $\lambda_{F}$ denotes the borrowing spread to LIBOR, $v_{t}$ denotes the future value of the derivative contract, $C$ denotes the value of the collateral and $P$ denotes the discount factor ${ }^{15}$. The equation for Funding Benefit Adjustment (FBA) is identical to Equation (3.9), except that $\lambda_{F}$ denotes the lending spread to LIBOR.

Funding Value Adjustment (FVA), which is the sum of FCA and FBA, captures the impact of funding and liquidity on the price of an uncollateralized derivative contract. FVA is the price adjustment designed to ensure that the dealer recovers from the client its average cost of funding when trading and hedging uncollateralized derivatives contracts. FVA represents the present value of the market funding costs, rather than accruing these costs over the life of the trade. FVA is the difference between a portfolio valued using a risk-free rate (e.g. OIS) as the discount rate and the same portfolio using the bank's average cost of funding as the discount rate.

There is a material, though not complete, overlap between FVA and DVA. We can express FVA as

$$
F V A=D V A+F C A
$$

As a bank's creditworthiness deteriorates, the DVA gains that it records on its payables will roughly offset the FVA losses that it records on its receivables. Conversely, as a bank's creditworthiness improves, the DVA losses that it records on its payables will roughly offset the FVA gains that it records on its receivables. Banks that implement an FVA framework effectively smooth the unintuitive earnings volatility associated with DVA. FVA varies depending on

\footnotetext{
${ }^{14}$ The practice of using the assets held as collateral for one client in transactions for another client.

${ }^{15}$ Typically a blended interest rate that takes into account the interest rate of the collateral and the funding rate.
} 
the size and tenor of a particular transaction, as well as a bank's own cost of funding.

A bank's funding cost is driven principally by its creditworthiness. Thus, FBA incorporates DVA. When a bank's creditworthiness deteriorates, its profits are magnified based on the effect of "double-counting". Some argue in favor of eliminating DVA and reporting FVA instead. But, accounting standards recognize DVA and require it to be included in derivatives valuation.

Traders view FVA as either an explicit cost or benefit that arises when an uncollateralized transaction is offset by a collateralized transaction. Since traders are charged for the cost of funding by their internal treasury desks, they argue that this "cost" should be reflected in the price of a derivative contract quoted to the client. Some dealers have begun to charge FVA even on collateralized derivatives. Dealers will apply an FCA when the collateral received cannot be consistently re-hypothecated or when the counterparty posts an unconventional form of collateral (e.g. corporate bonds). When the collateral cannot be re-hypothecated, the dealer is unable to fund the assets in the repurchase agreement (repo) market and generate cash to collateralize its hedge transactions, and therefore must borrow funds from its internal treasury or the money market. In this case, the collateral serves only to mitigate credit risk, but does not provide a funding benefit to the bank.

In contrast to traders, accountants believe that the fair value of a derivative contract should reflect its exit price, not the cost of funding. Both ASC 820 and IFRS $13^{16}$ define fair value as "the price that would be received to sell an asset or paid to transfer a liability in an orderly transaction between market participants at the measurement date".

As of the date of this writing, 11 major banks (e.g. Bank of America, Goldman Sachs, Deutsche Bank and UBS) have switched to an FVA framework. The adoption of FVA results in a one-time charge against income. In January 2014, the Chief Financial Officer of JP Morgan Chase indicated that “...we've now accumulated compelling evidence, both from transactions as well as industry pricing services that dealers are pricing funding into uncollateralized derivatives with a degree of consistency”. In the fourth quarter of 2013, JP Morgan Chase recorded a \$1.5 billion loss after implementing FVA in its derivatives and structures notes portfolios (J.P. Morgan Chase \& Co., 2014). Other banks, such as ING, insist that FVA should be ignored when pricing derivatives contracts.

In March 2012, University of Toronto professors John Hull and Alan White published a controversial paper in the Journal of Investment Management (Hull \& White, 2012) entitled “The Derivatives Discounting Dilemma”. In doing so, they sparked the theoretical debate about valuation that continues to this day. Inter alia, they argue against the use of FVA and cite the long-established principle in finance that the evaluation of an investment should depend only on the risk of that investment, not the way in which it is funded ${ }^{17}$. They argue in favor of the Law of One Price.

Critics of Hull and White (e.g. Castagna, 2012b) believe that funding costs are real and must therefore be included in the price of derivatives. They also argue that many of the assumptions underlying the Black-Scholes (1973) theory are unrealistic in practice, namely the completeness of markets, the ability to perfectly hedge all contingent claims and the ability to borrow and lend limitlessly at a risk-free rate. They argue that the Law of One Price no longer applies. Banks that are able to fund at favorable levels can offer their clients more attractive trade prices than competing banks funding at comparatively higher levels, ceteris paribus.

Unlike DVA, which is an accounting concept, FVA is real and must be priced accurately in order to remain competitive and to practice sound risk management. FVA cannot be neglected, as doing so would effectively skew the P\&L in favor of a particular trading desk and to the detriment of the larger organization.

FVA cannot be considered as an additive term in the pricing equation because a derivative contract's future cash flows depend on the funding decisions made at a future date. Pricing these cash flows today requires us to model funding decisions that will be made at some point in the future. Stated differently, the price of the derivative contract at time $t$ depends on one's funding strategy after time $t$. In turn, the funding strategy after time $t$ will depend on the derivative's price at times following time $t$. This recursive valuation system is quite difficult to implement, particularly when a trade's payouts are path-dependent (Brigo et al., 2013). Solving this recursive equation requires simultaneous backward induction and forward simulation.

Prior to the onset of the financial crisis, market participants did not distinguish between the rate used to discount derivative cash flows and the rate at which banks raised financing. Market participants used LIBOR not only as the risk-neutral discount rate for derivative cash flows, but also as a proxy for the cost of funding for banks. In the aftermath of the financial crisis, it became questionable whether banks could raise financing at LIBOR flat.

Rather than using a bank's own cost of funding, the majority of market practitioners argue that FVA should be

\footnotetext{
${ }^{16}$ Became effective on January 1, 2013.

${ }^{17}$ In later papers, Hull and White refine their view and accept that a portion of FVA can be recognized.
} 
benchmarked against a blended bank funding rate, in effect the "new LIBOR”. During the Q4 2013 earnings call, the Chief Financial Officer of JP Morgan Chase indicated a funding rate at "...a spread of approximately 50 basis points [above LIBOR]...” (J.P. Morgan Chase \& Co., 2014).

The mark-to-market of a trade calculated by an end-user could be significantly different than the mark-to-market of the same trade calculated by the end-user's bank counterparties. Let us assume that one bank has a funding spread of 50 basis points and further assume that another bank has a funding spread of 80 basis points. Each bank will value the same transaction differently, based on the differences in the funding cost. Disputes can arise when counterparties attempt to determine the "fair value" when entering into a new trade or when terminating or assigning (i.e. novating) an existing trade.

Let us assume that a bank raises funds at LIBOR plus 100 basis points. Ceteris paribus, the bank would quote to a commercial end-user receiving the fixed rate on an uncollateralized 10-year U.S. dollar interest rate swap approximately 4 basis points lower than a bank that were able to raise funds at LIBOR flat. Theoretically, banks with a lower cost of funding would be able to quote a higher fixed rate on the swap. Conversely, a client paying the fixed rate on an interest rate swap would likely benefit by trading with a bank with a higher cost of funding, as the end-user is effectively lending the bank money.

There is an extensive literature on CVA, DVA and FVA. For a detailed treatment of these adjustments, the reader is referred to Brigo, Morini and Pallavicini (2013).

\subsection{The Effect of Credit Risk and Funding}

In previous sections of the paper, we acquainted the reader with CVA, DVA and FVA in order to motivate discussion on the effect of credit risk and funding on the pricing of uncollateralized derivatives transactions. The amalgamation of CVA, DVA and FVA is sometimes referred to as Total Valuation Adjustment (TVA). Market participants who incorporate credit and funding into the pricing of an uncollateralized derivative contract would adjust the risk-neutral price of the contract according to the TVA. Knowledge of the hedging/replication strategy is fundamental.

In the case where one perfectly hedges self-default (see Section 3.2 of this paper), we can express TVA as

$$
T V A_{S D_{h}}=C V A+D V A
$$

since the FCA term disappears. In the more common case where one does not perfectly hedge self-default, we can express TVA as

$$
T V A_{S D_{u}}=C V A+D V A+F C A
$$

Given Equation (3.10), we can simplify Equation (3.12) as

$$
T V A_{S D_{u}}=C V A+F V A
$$

Trades are priced not only for their incremental market risk to a bank's portfolio, but also for their incremental counterparty, funding and capital implications to that bank's portfolio. Some practitioners argue that CVA, DVA and FVA must be made at the portfolio level, while others believe that these adjustments should be made at the trade level. The marginal contribution of a new trade could either increase or decrease a bank's counterparty and funding risks. The same principle holds true for pre-existing trades that are unwound.

Most large global banks have implemented a CVA pricing framework and incorporate the effects of CVA and DVA into the valuation of uncollateralized trades. Some banks even incorporate FVA into the valuation. Many smaller regional banks have not implemented a CVA pricing framework and do not incorporate the effects of CVA and DVA into the prices quoted to end-users. Since there are many computational approaches to FVA, valuation disputes will continue until we see a convergence in pricing methodology resulting from legislation and/or industry consensus. 


\section{Conclusion}

Under recently proposed legislation, end-users who hedge or mitigate commercial risks such as fluctuations in interest rates, foreign exchange and/or commodity prices with OTC derivative contracts will be exempt from mandatory central clearing and margin requirements. Banks are subject to higher capital charges for uncollateralized and partiallycollateralized trades and typically adjust the risk-neutral price of a trade to reflect CVA, DVA and, in some cases, FVA. At this time, most of the large global banks have incorporated CVA into the prices of derivatives contracts they quote to clients. These banks recover the cost of the CVA by pricing it upfront. Many smaller banks have not implemented a CVA pricing framework, allowing them to quote more competitive prices than the larger global banks and to compete for client business that would not have been possible before the large global banks implemented their CVA pricing frameworks.

In the wake of the financial crisis, we know that banks are susceptible to default. The inclusion of DVA has been widely debated and remains controversial. Fair-value accounting standards require the inclusion of DVA in derivatives prices, even though DVA is not formally recognized by Basel III.

There has been a lively debate as to the appropriateness of FVA. Academics Hull and White argue in favor of the Law of One Price and suggest that that evaluation of an investment should depend only on the risk of that investment, not the way in which it is funded. Critics assert that funding costs are real and must therefore be included in the price of derivatives. They also argue that the many of the assumptions that underlie the Black-Scholes (1973) theory are unrealistic in practice, namely the completeness of markets and the ability to borrow and lend limitlessly at a risk-free rate. They argue that the Law of One Price no longer applies. Banks that are able to fund at favorable levels can offer their clients more attractive trade prices than competing banks funding at comparatively higher levels, ceteris paribus.

Notwithstanding the theoretical debate, many banks have incorporated an FVA framework and charge clients for the funding costs associated with an uncollateralized trade. There is a material, though not complete, overlap between FVA and DVA. Given that accounting standards define fair value as "the price that would be received to sell an asset or paid to transfer a liability in an orderly transaction between market participants at the measurement date", accountants believe that the price of a derivative contract should reflect its exit price, not the cost of funding.

The amalgamation of CVA, DVA and FVA is often referred to as TVA. Market participants who incorporate credit and funding into the pricing of an uncollateralized derivative contract would adjust the risk-neutral price of the contract according to the TVA, ceteris paribus. Commercial end-users are urged to understand the impact of CVA, DVA and FVA on the price of new trades, terminations and novations. 


\section{References}

Abbate, R. (2014). CSA Discounting: Impacts on Pricing and Risk of Commodity Derivatives. Journal of Financial Risk Management, 3, 113-142. http://dx.doi.org/10.4236/jfrm.2014.33011

Bank for International Settlements (2009). Strengthening the Resilience of the Banking Sector. http://www.bis.org/publ/bcbs164.pdf

Black, F., \& Scholes, M. (1973). The Pricing of Options and Corporate Liabilities. Journal of Political Economy, 81, 637-654. http://dx.doi.org/10.1086/260062

Brigo, D., Morini, M., \& Pallavicini, A. (2013). Counterparty Credit Risk, Collateral and Funding: With Pricing Cases for All Asset Classes. Chichester: John Wiley \& Sons. http://dx.doi.org/10.1002/9781118818589

Burgard, C., \&Kjaer, M. (2010). PDE Representations of Options with Bilateral Counterparty Risk and Funding Costs. http://ssrn.com/abstract $=1605307$

Castagna, A. (2012a). The Impossibility of DVA Replication. Risk, November Issue.

Castagna, A. (2012b). Yes, FVA Is a Cost for Derivatives Desks-A Note on “Is FVA a Cost for Derivatives Desks?” by Prof. Hull and Prof. White. http://ssrn.com/abstract=2141663

Citibank(2009). 1st Quarter Earnings Release. http://www.citigroup.com/citi/press/2009/090417a.htm

Financial Accounting Standards Board (FASB) (2011). Accounting Standards Codification (ASC), 820-10-35-17. http://asc.fasb.org/

Hull, J., \& White, A. (2012). LIBOR vs. OIS: The Derivatives Discounting Dilemma. Journal of Investment Management, 11 , 14-27.

International Swaps and Derivatives Association, Inc. (2014). ISDA Insight Survey: Derivatives Vital to End-Users, but Fragmentation a Concern. http://www2.isda.org/newsroom/press-releases/

J.P. Morgan Chase \& Co. (2014). Q4 2013 Earnings Call. http://www.morningstar.com/earnings/61444113-jpmorgan-chase-co-q4-2013.aspx

Watt, M. (2011). Corporates Fear CVA Charge Will Make Hedging Too Expensive. Risk, October Issue. 


\section{Appendix A}

If we assume that trades are subject to netting and that any collateral can be described by the instantaneous model ${ }^{18}$, then a counterparty-level CVA can be computed in a Monte Carlo simulation as follows:

1. Generate market scenarios $j$ (interest rates, foreign exchange rates, commodity prices, etc.) for each of the future time points $t_{k}$.

2. For each simulation time point $t_{k}$ and scenario $j$ :

a. For each trade $i$, calculate the trade value $V_{i}^{(j)}\left(t_{k}\right)$.

b. Calculate the portfolio value $V^{(j)}\left(t_{k}\right)=\sum_{i=1}^{N} V_{i}^{(j)}\left(t_{k}\right)$.

c. If there is a margin agreement in place, and if we denote the threshold as $H$, then calculate the collateral $C^{(j)}\left(t_{k}\right)=\max \left\{V^{(j)}\left(t_{k}\right)-H, 0\right\}$ available at time $t_{k}$.

d. Calculate the counterparty-level exposure $E^{(j)}\left(t_{k}\right)=\max \left\{V^{(j)}\left(t_{k}\right)-C^{(j)}\left(t_{k}\right), 0\right\}$. If there is no margin agreement in place, then $C^{(j)}\left(t_{k}\right)=0$.

3. After generating a sufficient number of market scenarios, which we denote by $N$, compute the discounted expected exposure, denoted as $E$, by averaging over all of the market scenarios at each time point $e^{*}\left(t_{k}\right)=$ $\frac{1}{N} \sum_{j=1}^{N} D^{(j)}\left(t_{k}\right) E^{(j)}\left(t_{k}\right)$, where $D$ is the discount factor.

4. Compute CVA as $C V A_{k}=(1-R) \sum_{k} e^{*}\left(t_{k}\right)\left[P\left(t_{k}\right)-P\left(t_{k-1}\right)\right]$, where $R$ denotes the recovery rate and $P(t)$ denotes the unconditional cumulative probability of default up to time $t$.

\section{Appendix B}

\begin{tabular}{|c|c|c|c|c|c|c|c|c|c|}
\hline \multirow[b]{2}{*}{$\begin{array}{c}\text { time } \\
\text { (years) }\end{array}$} & \multirow[b]{2}{*}{$\begin{array}{l}\text { discount } \\
\text { factor }\end{array}$} & \multicolumn{4}{|c|}{ counterparty } & \multicolumn{4}{|c|}{ self } \\
\hline & & $\begin{array}{l}\text { default } \\
\text { prob. }\end{array}$ & $\begin{array}{c}\text { survival } \\
\text { prob. }\end{array}$ & $\mathrm{EE}$ & CVA & $\begin{array}{l}\text { default } \\
\text { prob. }\end{array}$ & $\begin{array}{c}\text { survival } \\
\text { prob. }\end{array}$ & ENE & DVA \\
\hline 0 & 1.0000000 & - & $100.00 \%$ & - & - & - & $100.00 \%$ & - & - \\
\hline 1 & 0.9965491 & 0.0021793 & $97.35 \%$ & 0.3469189 & 0.0002160 & -0.0017017 & $97.94 \%$ & -0.3060662 & -0.0001906 \\
\hline 2 & 0.9840772 & 0.0021216 & $94.77 \%$ & 0.4370431 & 0.0003476 & -0.0016667 & $95.92 \%$ & -0.3776559 & -0.0003004 \\
\hline 3 & 0.9610225 & 0.0020654 & $92.27 \%$ & 0.4461003 & 0.0003858 & -0.0016323 & $93.94 \%$ & -0.3919318 & -0.0003389 \\
\hline 4 & 0.9317875 & 0.0020107 & $89.82 \%$ & 0.4365321 & 0.0003965 & -0.0015986 & $92.00 \%$ & -0.3664442 & -0.0003329 \\
\hline 5 & 0.9050373 & 0.0019575 & $87.44 \%$ & 0.3935901 & 0.0003799 & -0.0015657 & $90.11 \%$ & -0.3432151 & -0.0003313 \\
\hline 6 & 0.8748888 & 0.0019057 & $85.13 \%$ & 0.3327619 & 0.0003299 & -0.0015334 & $88.25 \%$ & -0.2880892 & -0.0002856 \\
\hline 7 & 0.8457664 & 0.0018552 & $82.88 \%$ & 0.2676568 & 0.0002678 & -0.0015018 & $86.43 \%$ & -0.2245022 & -0.0002246 \\
\hline 8 & 0.8157487 & 0.0018061 & $80.68 \%$ & 0.1901820 & 0.0001939 & -0.0014708 & $84.65 \%$ & -0.1553557 & -0.0001584 \\
\hline 9 & 0.7867764 & 0.0017583 & $78.54 \%$ & 0.1009652 & 0.0001026 & -0.0014405 & $82.90 \%$ & -0.0809573 & -0.0000822 \\
\hline 10 & 0.7587580 & 0.0017117 & $76.47 \%$ & 0.0079451 & 0.0000080 & -0.0014108 & $81.19 \%$ & -0.0063200 & -0.0000064 \\
\hline
\end{tabular}

\footnotetext{
${ }^{18}$ The instantaneous model assumes that collateral is delivered immediately and that trades can be liquidated immediately. These assumptions materially affect the exposure distribution.
} 